\title{
Sex Preferences Among Mothers Delivering at Patan Hospital
}

\author{
Chhetri UD, ${ }^{1}$ Ansari I, ${ }^{1}$ Bhandary $S,{ }^{2}$ Adhikari $\mathrm{N}^{1}$
}

\author{
${ }^{1}$ Department of Pediatrics \\ ${ }^{2}$ Department of Community Medicine \\ Patan Academy of Health Sciences \\ Patan Hospital, Nepal
}

Corresponding Author

Uma Devi Chhetri

Department of Pediatrics

Patan Academy of Health Sciences

Patan Hospital, Nepal

Email: umadevichhetri@pahs.edu.np

Citation

Chhetri UD, Ansari I, Bhandary S, Adhikari N. Sex Preferences in Mothers Delivering at Patan Hospital. Kathmandu Univ Med J 2011;36(4):229-232.

\begin{abstract}
Background

High sex ratios at birth (SRB) are seen in China, Taiwan, South Korea, parts of India and Vietnam. The imbalance is the result of son preference, accentuated by declining fertility. Prenatal sex determination and female feticides are common in many countries. It is reflected in sex ratio
\end{abstract}

\section{Objective}

To determine reasons for the preferences for different sex; to find out whether there is altered sex ratio at birth and to find out whether female feticide are common among women who had abortion.

\section{Method}

It is a prospective study. Women who had previous history of abortion and had delivered at Patan Hospital in the year 2066 were interviewed as per questionnaires.

\section{Results}

Among 560 women with total live births of 965, (462 male and 503 female) during their life time the overall sex ratio was 92 male per 100 female birth; total abortions were 663. Preferences for male were $10 \%$, female $15.4 \%$ and either was for $74 \%$. The reason for male preference was to continue family lineage, to bring honor, old age security, and performing funeral rites while the reasons for daughter preferences were that they understand mother's pain, help in household work. The sex ratio of the babies born during the study period was 113 male per 100 female births. The Sex ratio at birth from $1^{\text {st }}$ to $6^{\text {th }}$ deliveries was $61,79,101,210,286$ and 1100 male per 100 female birth respectively. Prenatal sex selection was $8 \%$ (by USG) but none had sex selected abortion.

\section{Conclusion}

Sex ratio of those delivered during the study period was skewed (136 boys per 100 girls) towards male. There was shift in SRB in $4^{\text {th }}$ and subsequent pregnancies in favor of boys. As the male sex ratio increased the number of induced abortion decreased in subsequent pregnancies.

\section{KEY WORDS}

Feticide, Induced abortion, Sex preferences, Sex ratio.

\section{INTRODUCTION}

Higher sex ratio at birth (SRB) (108 boys per 100 girls or higher) are seen in China, Taiwan, South Korea, parts of India and Vietnam. ${ }^{1,2}$ The imbalance is the result of son preference, accentuated by declining fertility. ${ }^{1}$ Prenatal sex determination and female feticide is common in many countries. It is reflected in by altered sex ratio at birth. Sex ratio may be computed for entire population (overall sex ratio), or for specific age groups or for birth cohorts as sex ratio at birth (SRB). ${ }^{2,3}$ Standard SRB for human population is 102-106 male births per 100 female births. ${ }^{3}$ SRB values more than 108 reveals human intervention before or during pregnancies when the measured sample is large enough $(>10,000) .^{3}$

In Nepal, 2001 census reveals overall sex ratio of 99.8 males 
per 100 female which was about same as 99.5 in 1991 and 98.6 on $1971 .^{7}$ Age specific sex ratio for 0-4 yrs was 103 boys per 100 girls, for 5-9, $102^{4}$ boys for 100 girls and for 10-14 it was 106 boys for 100 girls. Region specific sex ratio for age less than 1 yr was 104.8 in terai, 103.9 in hilly region and 102.6 in mountain. Sex ratios of those younger than 1 year (SRB1) of age were over 106 in seven districts in the terai (Saptari, Siraha, Dhanusa, Mahottari, Bara, Parsa and Kapilbastu) and one hill district of Gorkha. The SRB1 is used as a proxy indication of prenatal sex selection. The sex ratio at birth among women who said they had completed their families or had been sterilized was 116 males per 100 females, which is slightly higher than values of 105 among all women participating in the Nepal Demographic and Health Survey. ${ }^{5}$

Women go for induced abortion for different reasons like enough children, do not want child at that time or want male child.

Objective of this study was to determine the preferences for different sex, the reasons for such preferences, to find out whether there is altered sex ratio at birth and to find whether female feticide is common among women who had abortion.

\section{METHODS}

It was a prospective study. Women who had previous history of abortion and had delivered at Patan Hospital in the year 2066 (Baisakh - Chaitra) were interviewed according to preformed questionnaire after taking verbal consent. The completed questionnaires were entered into computer following manual editing and coding. After cleaning and consistency checks, the data set was transferred to the SPSS software programme.

Sex ratio for the 1st and subsequent live born babies were recorded and analyzed. The sex of abortuses, nature of abortion (spontaneous or induced) and reasons for induction of abortion were analyzed.

Mother's preference for sex of the baby, reasons for preference, whether there was pressure on mother from family members and mother's knowledge about different methods of sex determination were studied.

\section{RESULTS}

Total 560 women who had recently delivered at Patan Hospital were interviewed. The highest numbers of women were Newar (30.2\%), followed by Brahmin (25.2\%), Tamang, Lama (16\%), Chhetri (15.4\%) and others (13.4\%). Most of the women were Hindus (84\%), followed by Buddhist (12\%), Christian (3.3\%) and Muslim (0.07\%). Most of the women were from Kathmandu (42\%) and Patan district (40\%), followed by Bhaktapur (11\%) and other places (7\%).
Table 1. Total number of live births with birth order and sex in the women's life.

\begin{tabular}{lllll} 
Birth order & Total live births & Male & Female & Sex ratio \\
\hline I & 235 & 89 & 146 & 61 \\
\hline II & 341 & 150 & 191 & 79 \\
III & 254 & 128 & 126 & 101 \\
\hline IV & 93 & 63 & 30 & 210 \\
\hline V & 29 & 20 & 7 & 286 \\
\hline VI \& subse- & 12 & 11 & 1 & 1100 \\
quent & & & & \\
Total & 962 & 462 & 503 & 92 \\
\hline
\end{tabular}

Total number of live births during their married lives among 560 women were 965 (462 males and 503 females) with overall sex ratio of 92 male per 100 female live birth. Total abortions among 560 women during their life time were 663 [404 (72\%) spontaneous and 259 (46\%) induced abortion]. In this population seven neonatal deaths and 15 (3\%) still births were also reported.

Out of 560 deliveries including eight twin sets, 327 were male and 241 female with an overall sex ratio at birth (SRB) of 136 male per 100 female.

Table 2. Number of live births and abortions according to the birth order.

\begin{tabular}{|llllll|}
\hline Birth order & $\begin{array}{l}\text { No. } \\
\text { of live } \\
\text { birth }\end{array}$ & $\begin{array}{l}\text { Total } \\
\text { no. of } \\
\text { abortion }\end{array}$ & $\begin{array}{l}\text { Sponta- } \\
\text { neous } \\
\text { abortion }\end{array}$ & $\begin{array}{l}\text { Induced } \\
\text { abortion }\end{array}$ & $\begin{array}{l}\text { Sex } \\
\text { ratio }\end{array}$ \\
\hline 1st & 235 & 310 & 228 & 82 & 61 \\
\hline 2nd & 341 & 333 & 118 & 115 & 79 \\
\hline 3rd & 254 & 86 & 44 & 42 & 101 \\
\hline 4th & 93 & 27 & 11 & 16 & 210 \\
\hline 5th & 29 & 6 & 2 & 4 & 286 \\
\hline 6th \& & 12 & 1 & 1 & 0 & 1100 \\
\hline subsequent & & & & & \\
\hline Total & 962 & 663 & 404 & 259 & \\
\hline
\end{tabular}

Figure 1. Relation of sex ratio with percentage of induced and spontaneous abortion according to birth order.

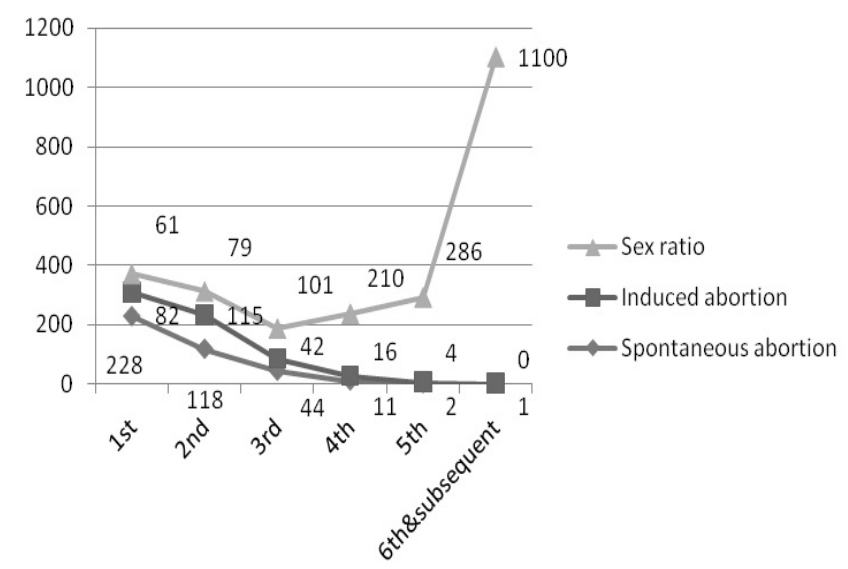


The birth-order-wise sex ratio was 61 male per 100 female for first birth and 79, 101, 210, 286, 1100 male per 100 female for $2^{\text {nd }}, 3^{\text {rd }}, 4^{\text {th }}, 5^{\text {th }}$ and $6^{\text {th }}$ birth. (Table 1 ) The sex ratio at birth increased in subsequent pregnancies. There was shift in SRB in $4^{\text {th }}$ and subsequent pregnancies in favor of boys. As the sex ratio increased the number of induce abortion decreased which showed that the women who had SRB in favor of girl child in $1^{\text {st }}$ and $2^{\text {nd }}$ births, had increased number of abortion contrast to women who had SRB in favor of boys in $3^{\text {rd }}$ and $4^{\text {th }}$ pregnancy onwards.

On enquiring the reason for preference of son, the following were the responses: further source of continuing family lineage (51\%), religious advantage (20\%), pride and power (16\%) and old age security. Two hundred and seventy five (49\%) expressed preference for daughter because they love mothers (45\%) help in household chore (19\%), understand mother's pain (16\%) and for old age security (15\%).

Preferences for daughter in $1^{\text {st }}$ pregnancy was 87 (15.4\%), son was $60(10.4 \%)$ and either 413 (74\%). When enquired for preference of sex when more than one child was born ed $5 \%$ voted for preference for boy, $5 \%$ for girl and $72 \%$ for equal sex preference and $16 \%$ did not care for the sex of the child.

The ratios of abortion to live births in 1st to 6th pregnancies were $1.32,0.98,0.34,0.29,0.29$ and 0.08 respectively. (Table 2)

Five hundred forty-nine (98\%) mothers knew about different methods of sex determination; $96 \%$ knew about USG, 3\% about amniocentesis and 1\% about traditional method. 501 (89\%) had USG examination during present pregnancy. Forty two (8\%) mothers had USG examination for fetal sex determination while others did it for general well being of the fetus but none had induced abortion following prenatal sex determination.

The study found that there was great pressure on women to give birth to a son from husband (58\%), mother in laws (50\%) and father in laws (36\%).

On enquiring whether they want to use 'sex pills'; hypothetical pills which when consumed will give them desired sex baby, $21 \%$ wanted to use it.

\section{DISCUSSION}

Out of 560 women studied, $93 \%$ of the mothers were educated, contrast to $68 \%$ literate mother in CREPHA (Centre for Research on Environment Health and Population Activities) with $28 \%$ having higher education up to master degree. ${ }^{4}$ Ninety percent of father were educated out of which $40 \%$ were having higher education. One percent of the father and $7 \%$ of the mothers were illiterate.

The predominant cast in our study was newar (30\%), Brahmins (25\%), tamang lama (16\%), chhetri (12\%) and others. While the predominant caste, ethnics and religious groups presented in the CREPHA sample were Yadav in
Dhanusa and Kapilbastu; muslims in Kapilbastu; Tharus and Terai Dalits in Parsa; and hill Brahamin, Chhetri and Magar in Gorkha.

The average age of the mother was $27.8 \pm 4.5$ years; youngest being 17 and oldest being 39 years of age. While the average age of the mother was 30 years in CREHPA; youngest was 15 and oldest was 49 years. ${ }^{4}$ The average age of the father was found to be 32 years with a standard deviation of 4.9 years; youngest being 20 and oldest being 50 years of age.

In our study population, we found a sex ratio at birth for live birth to be 136 boys per 100 girls. This is skewed towards male sex more than that of UNFPA report. ${ }^{1}$ There is highly significant shift in SRB in 4th and subsequent pregnancies in favor of boys similar to the study by N. Adhikari. ${ }^{6}$ This high degree of statistical significance $(P=.0000)$ can be possible because of pre-natal sex determination and intervention. Overall sex ratio of 87 male per 100 female is less than that of 1991 census of Nepal.

China tops the list of countries with a skewed sex ratio at birth with 120 males for every 100 females born in 2005 and as high as 130 in several provinces while natural sex ratio is around 105 male per 100 female. ${ }^{1}$ In China since 1982 , there has been a strong rise in sex ratio of children age $0-4$ from 106 to 120 , with the sex ratios of younger age groups becoming higher than those of older age groups. ${ }^{7}$

In India, the 2001 nation wide census revealed SRB to be 108 and 120 in some northern and western states.5In 2006 the Sex ratio at birth was 110 in Viet Nam for about 30,000 births. $^{8}$

In 2005, the estimated overall sex ratio was 107.5 males per 100 females in India, as against 106.8 in China, 106 in Pakistan and 104.9 in Bangladesh, the four countries that accounted for $43 \%$ of the world's population in $2005 .{ }^{8}$ As shown in the fig 1 , sex ratio at birth increased in subsequent pregnancies. As the sex ratio increases the number of induced abortion as reported had decreased in subsequent pregnancies. Almond D et al found normal sex ratios at first parity but rising with parity if there were no previous son in Asian immigrants to Canada. They find fertility responds strongly to the sex composition of older children for first generation families. ${ }^{9}$ Similar report was given by Jason Abrevaya in US. He reported high boy -birth percentages after 1980 among later children (most notably 3rd and 4th children) born to Chinese and Asian Indian mother. These mothers are found to be significantly more likely both to have a terminated pregnancy and to give birth to a son when they have previously only given birth to girls. These findings are consistent with a simple dynamic model of the gender -selection. ${ }^{10}$

Most of the mothers had no preferences for sex in first pregnancy which is similar to CREHPA and UNFPA reports in 2007. Preferences for son in first pregnancy is lower than daughter while males are preferred than female in CREHPA 
reports. ${ }^{4}$ Importance of daughters were because of their love to mother and help in household chores. In CREPHA daughters were not desired because of the need to pay dowry in their marriage and because daughters could not look after home after their marriage. The report might be because the study was done in most of the Terai area where dowry is practiced while it is not practiced in valley as much. In our study we did not ask why girls were not desired.

Sons are preferred over daughters for different reasons. Number of child birth in a family is determined by the birth of a male child. More abortions and more children are seen in families till there is a male child birth. Women are pressurized for giving birth to male child by different members of the family or society for different reasons. Preferences for sons were for continuing family lineage, religious advantage pride and power and old age security in valley while the cause was mostly because of future source of economic support, to bring dowry and old age security in Terai ethnic communities as shown by CREPHA report. ${ }^{4}$

In our study, $89 \%$ of mothers had prenatal USG while it was $57 \%$ in UNFPA report. ${ }^{2}$ USG was used for fetal sex determination in $8 \%$ in our study while it was 3\% in UNFPA report, and $26.5 \%$ CREPHA report. ${ }^{2,4}$ According to UNFPA report $14 \%$ had induced abortion following prenatal sex determination while none had admitted this in our study though prenatal sex determination was $8 \%$ and induced abortions were $48 \%$. Women prefer daughter in their 1 st pregnancy in our study similar to CREPHA. ${ }^{4}$

The study found that there was great pressure on women to give birth to a son from husband (58\%), mother in laws (50\%) and father in laws (36\%) similar to $42 \%, 41 \%$ and $4 \%$ respectively in CREHPA and UNFPA. ${ }^{4}$ The type of threat was continuous scolding (86\%), threaten to marry again (40\%), not providing proper meal or dress (38\%), hit or beat (18\%) and contempt by family member (94\%) in CREHPA.

The rate of contraceptive use in our study was $40 \%$, while it was reported to be $25 \%$ by Leone $\mathrm{T}$, et al. The rate of contraceptive use increased to $33 \%$ if there had no sex preference, a increase of eight percentage points. Contraceetive use varied widely according to sex composition. For example for families with 3 children $44 \%$ of women who had 3 boys used a method, but only $6 \%$ of those who had 3 daughters do so. ${ }^{11}$

\section{CONCLUSION}

Sex ratio during the study period is skewed (135:100) towards male while overall sex ratio is less than that of 1991 census. There is significant shift in SRB in fourth and subsequent pregnancies in favor of boys. Male sex ratio at birth increased in subsequent pregnancies. As the male sex ratio increased the number of induced abortion decreased. This shows that women choose to be sterilized once they had "adequate" number of baby boys.
Though women did not admit sex selective abortion, highly significant shift in SRB in fourth and subsequent pregnancy in favor of boys and increased male sex ratio and decreased abortion in subsequent pregnancies could not be ruled out the male sex preferences in women delivered in Patan Hospital.

Majority of women did not care for the sex of the child in first pregnancy others preferred female than male child. Prenatal sex selection was found to be $7.5 \%$. In conclusion women had considerable pressure to bear a son from husbands, mother in laws and father in laws.

\section{REFERENCES}

1. Zofeen E. International Sex -selection technology and 163 million 'Missing Women. Source: IPS. Experts the 4th Asia Pacific Conference on Reproductive and Sexual Health and Rights.

2. Ganatra B. Maintaining Access to Safe Abortion and Reducing Sex Ratio Imbalances in Asia. Reproductive Health Matters 2008; 16 (31 Supplement) 90-98.

3. CZ Gulimoto LPED/IRD, Paris UNFPA. Characteristic of Sex Ratio Imbalance in India and Future Scenarios. Paper presented at the 4th Asia Pacific Conference on Reproductive and Sexual Health and Rights. Oct, 29-31, 2007. Hyderabad, India.

4. Sex selection: Pervasiveness and preparedness in Nepal. Centre for Research on environment health and population activities (CREHPA) and UNFPA. Paper presented at 4th Asia Pacific Confrence on Reproductive and sexual health rights. Oct, 29-31, 2007. Hyderabad, India.

5. Leone T, Mathews Z and Zuanna GD. Impact and Determinants of Sex Preference in Nepal. International Family Planning Perspectives June $2003 ; 29,(2)$.

6. Adhikari N, Ghimire A, Ansari I. Sex preferences in Urban Nepal. Journal of Institute of Medicine Aug 2008; 80:219-23.

7. Schuzhuo Li. Imbalanced Sex Ratio at Birth and Comprehensive Intervention in China. 4th Asia Pacific Conference on Reproductive and Sexual Health and Rights 29-31 October 2007; Hyderabad, India.

8. New "Common Sense ": Family-Planning Policy and Sex Ratio in Viet Nam.4th Asia Pacific Conference on Reproductive and Sexual Health and Rights 29-31 October 2007; Hyderabad, India.

9. Almond D, Edlund L, Milligan K. Son Preference and the Persistence of Culture: evidence from Asian immigrants to Canada. National Bureau of Economic Researches. 1050 Massachusetts Avenue, Cambridge, MA 02138, Oct 2009.

10. Jason Abrevayar. Are there missing girls in the United States? Evidence on gender preference and gender selection [Internet]. [Place unknown]: Sex, power and politics blog;September 2005. [updated $2005 \mathrm{Sep}$; cited $2011 \mathrm{Jul}$ 15]. Available from:hhtp://www. http://pol285.blog.gustavus.edu/files/2009/08/Abrevaya_Missing_ Girls_in_the_US.pdf

11. Leone T, Mathew Z, Zuanna GD. Impact and Determinants of Sex Preference in Nepal. International Family Planning Perspectives, 2003, 29(2):69-75. 